\title{
Perceived Pollution and Residential Sorting in Germany: Income May Not Sort, But it Helps to Escape
}

\section{November 6, 2020}

\author{
Tobias Rüttenauer ${ }^{\dagger}$ and Henning Best ${ }^{\ddagger}$ \\ $\dagger$ University of Oxford, Nuffield College, New Road, Oxford OX1 1NF, United Kingdom \\ $\ddagger$ University of Kaiserslautern, Department of Social Sciences, Erwin-Schrödinger-Str. 57, \\ 67663 Kaiserslautern, Germany
}

\begin{abstract}
The disproportionate exposure of minorities and socio-economically disadvantaged households to environmental pollution is often explained by selective migration or sorting mechanisms. Yet, previous empirical findings remain inconclusive. In this study, we offer an explanation for mixed findings by focusing on the selective outmigration process triggered by environmental pollution. We use household-level panel data of the German SOEP from 1986 to 2016 and within-household estimates of correlated random effects probit models. More precisely, we test if the subjective impairment through air pollution selectively affects the probability of out-migration according to income and minority status. We find that perceived air pollution has a stronger effect on the likelihood of moving for households experiencing an income increase. Surprisingly, we find only small and imprecise differences between native German and first generation immigrant households, and a relatively large proportion of this difference can be explained by income. This indicates that selective out-migration processes substantially differ from selective in-migration processes, and environmental inequality research should more carefully distinguish the single steps of neighbourhood sorting.
\end{abstract}

\section{KEYWORDS}

environmental inequality; correlated random effects; German SOEP;

neighbourhood attainment; neighbourhood sorting; selective out-migration 


\section{Introduction}

Environmental inequality describes the unequal distribution of environmental hazards or environmental pollution across different groups of citizens. As part of the broader environmental justice debate (Bullard, 1990), research in the field generally hypothesises that disadvantaged groups, like minorities or socioeconomically disadvantaged citizens, bear a disproportionately high burden of environmental pollution. Accordingly, previous studies in the United States (e.g. Ard, 2015; Ash \& Boyce, 2018; Banzhaf, Ma, \& Timmins, 2019; Crowder \& Downey, 2010; Mohai \& Saha, 2015) and in Europe (e.g. Diekmann \& Meyer, 2010; Glatter-Götz, Mohai, Haas, \& Plutzar, 2019; Pasetto, Mattioli, \& Marsili, 2019; Rüttenauer, 2018) have documented the unequal distribution of environmental hazards across different social groups.

Given the strong impact of environmental pollution on health and other spheres of life (e.g. Landrigan et al., 2018), it is an important aim to understand the causes of this severe dimension of social inequality. One explanation for the disproportionate exposure of low-income and minority households is that marginalised groups selectively move towards polluted areas while advantaged groups are more likely to escape those areas, which is called the selective migration or sorting thesis. However, findings on the causal process explaining the high exposure of disadvantaged groups remain inconclusive so far (for an overview see e.g. Banzhaf et al., 2019). While some studies find support for the thesis that minorities and poor households selectively sort into more polluted areas, others show no evidence for selective migration processes. A possible explanation for these contrasting findings might be that different ways of selectivity apply to out- an in-migration processes. Still, only few studies have tried to separate the different stages of selective migration.

In this study, we provide new insights on the process of environmental inequality by focusing on the stage of selective out-migration. More precisely, we analyse whether the ability of escaping polluted areas depends on income and minority status. The first stage of the selective migration process has received little attention so far, as most studies either combine out- and in-migration to a sorting process or focus on selective in-migration only. This is a shortcoming, as separating the two stages might be important to fully comprehend the course of selective sorting. We argue that different theoretical mechanisms apply to the out- and in-migration stage of selective sorting. For the in-migration stage, several theoretical mechanisms point to minority disadvantages in the returns to migration. Still, this is not the case regarding the out-migration process. In the stage of out-migration, a relatively large proportion of the minority disadvantage can be ascribed to socio-economic differences, as for instance discrimination is 
likely to have a higher impact on in- than on out-migration processes.

We use household-level panel data of the German SOEP from 1986 to 2016 and within-household estimates to test if the effect of subjectively perceived air pollution on the probability of out-migration depends on income and minority status. By relying on a subjective measure, we avoid the assumption that households are aware of actual levels of pollution. Thus we conduct a direct test of whether people are more likely to move when they perceive higher levels of air pollution, which constitutes a necessary precondition for any relation with objective pollution levels. Furthermore, we use within-household estimators to capture behavioural changes due to temporal variation in the perceived level of air pollution. This allows us to test if the ability to leave an unfavourable place of residence varies with income and minority status. As we focus on the selective out-migration stage here, we do however not investigate where people end up after out-migration, which has been the focus of other studies (Best \& Rüttenauer, 2018; Crowder \& Downey, 2010).

The results show that income indeed interacts with the effect of perceived environmental pollution on the moving probability: households are more likely to escape pollution after increases in income. We also find evidence for selective migration based on minority status, as pollution has a lower effect on the moving probability for immigrant households. The disadvantages are however rather weak and over twenty percent are explained due to income differences. This contrasts results from earlier studies (Best \& Rüttenauer, 2018; Crowder \& Downey, 2010) investigating the second stage of the process - selective in-migration - and highlights the importance of distinguishing between the two stages of selective migration. Moreover, it offers an explanation for the diverging results in previous studies.

\section{Theoretical background}

In this section, we outline the theoretical reasoning for selective sorting processes according to environmental pollution. We discuss theoretical arguments and empirical findings for ethnoracial minorities like Blacks and Hispanics in the US context. In the German context disadvantaged minorities are mostly immigrant minorities and their descendants. Obviously, these groups differ in many important dimensions. Still, based on previous findings, we assume that general processes of environmental inequality apply to immigrant minorities in Germany and ethnoracial minorities in the US alike. For instance, previous research indicates that Blacks in the US and immigrant minorities in Germany experience similar discriminatory disadvantages on the labour market (Quillian et al., 2019) and on the housing market (Auspurg, Schneck, \& Hinz, 2019). Fur- 
thermore, findings on environmental inequality in the German speaking area for immigrant minorities resembles results from the US for ethnoracial minorities (Glatter-Götz et al., 2019; Rüttenauer, 2019).

Besides selective sorting, environmental inequality can also result from selective siting of disamenities (Banzhaf et al., 2019; Depro, Timmins, \& O'Neil, 2015; Hamilton, 1995; Mohai \& Saha, 2015; Pastor, Sadd, \& Hipp, 2001). Selective siting assumes that polluting facilities are located disproportionately close to minorities or economically disadvantaged residents, thus hypothesising an opposite temporal order than selective migration. In this article, we do not discuss the selective siting argument in detail, as our study focuses on selective migration only.

The selective migration argument of environmental inequality states that the unequal exposure of disadvantaged citizens stems from selective migration (or sorting) processes into and out of polluted areas (e.g. Banzhaf, Sidon, \& Walsh, 2012; Depro et al., 2015). In general, households try to satisfy their preferences including those for public goods - by moving between neighbourhoods (Clark \& Coulter, 2015). This theoretical argument includes the processes of selective outand in-migration. Yet, we show in this section that it is important to distinguish between selectivity on income and selectivity on race / minority status, as this leads to different predictions regarding in- and out-migration processes. Thus, we outline the theoretical processes based on income first and subsequently discuss reasons for selectivity based on minority status.

\subsection{Income}

Because households prefer to live in clean neighbourhoods (Bayer, Keohane, \& Timmins, 2009), the demand for high quality neighbourhoods is higher than the demand for low quality neighbourhoods. Given the finite amount of high quality neighbourhoods, this also raises the housing and land prices in clean areas. As previous research has shown that an increase in income also increases the 'willingness to pay' for environmental goods (Banzhaf et al., 2012; Liebe, Preisendörfer, \& Meyerhoff, 2010; Meyer \& Liebe, 2010), we would expect that the threshold for leaving a neighbourhood because of environmental pollution declines with an increasing income (Banzhaf \& Walsh, 2008, 2013). As a result, affluent households are more likely to leave polluted areas. The same argument applies to selective in-migration: due to their greater 'willingness to pay', affluent households are willing (or able) to afford the higher housing prices in clean neighbourhoods. Consequently, affluent households are more likely to sort into less polluted areas once they decided to move. In sum, the theoretical reasoning predicts that both - out- and in-migration - processes are selective based on 
income, and households sort into cleaner neighbourhoods when their income increases.

In general, studies using spatially aggregated longitudinal data to analyse selective migration processes based on income report mixed results (for a complete overview see e.g. Banzhaf et al., 2019; Mohai \& Saha, 2015). For instance, Banzhaf and Walsh (2008) find some support for lower income trajectories in areas which previously received a Toxics Release Inventory (TRI) facility, and Gamper-Rabindran and Timmins (2011) find an increase in average income after the clean-up of hazardous waste sites. However, others contradict the selective migration argument by finding no changes in poverty rates (Been \& Gupta, 1997) or the average income (Downey, 2005) after the siting of industrial facilities. In contrast, studies at the household level offer more homogeneous results: in the US, affluent households move into neighbourhoods with higher distances to industrial facilities (Crowder \& Downey, 2010), and are less likely to be in permanently high-pollution moving trajectories (Pais, Crowder, \& Downey, 2014). In Germany, Best and Rüttenauer (2018) find higher moving returns due to income: income helps to reduce the environmental burden when moving to a new place of residence. Though the results at the household level confirm the process of selective in-migration based on income, the income-pollution disadvantages of in-migration are rather small, and especially much smaller than disadvantages of minorities in the in-migration stage. Nevertheless, none of the above mentioned studies explicitly tests for income differentials in out-migration processes. Thus, we lack an empirical test for the income dependence of the first stage of the sorting process: selective out-migration.

\subsection{Race / minority status}

When explaining the pollution disadvantage of minority residents, scholars often refer to similar mechanisms as outlined above, thus arguing that majority households are more likely than minority households to leave polluted areas and more likely to end up in clean areas (Banzhaf et al., 2019; Mohai \& Saha, 2015). This is often explained by the racial income-inequality thesis. As minority households, on average, have lower socio-economic resources, they also have a lower 'willingness to pay' for (or ability to afford) environmental goods as majority households. Consequently, minorities have a lower likelihood of moving out of hazardous areas, and a lower likelihood of moving into clean neighbourhoods (Depro et al., 2015). However, previous studies investigating selective in-migration only find marginal reductions of the minority disadvantage in in-migration processes when controlling for income (e.g. Best \& Rüttenauer, 2018; Crowder \& Downey, 2010). This rather contradicts the idea that minority disadvantages are 
the result of lower economic resources. Thus, other mechanisms seem to drive the selective in-migration of minorities into polluted areas.

A second, often stated, argument for selective migration processes by minority households is discrimination on the housing market. In line with this argument, previous studies have found that minorities experience general disadvantages on the housing market in the US (e.g. Ewens, Tomlin, \& Wang, 2014; Turner \& Ross, 2005) and to a similar extent in Europe and Germany (Auspurg et al., 2019). Accordingly, minorities do not get access to good and clean neighbourhoods due to discrimination, and thus end up in more polluted areas. This implies incomeindependent migrational barriers on the housing market, which corresponds to the remaining minority disadvantage after controlling for income.

Nevertheless, if discrimination is responsible for selective migration processes of minority households, this should mainly affect the destination when moving (selective in-migration) and not the probability of moving (selective outmigration) itself. As put by Massey and Denton (1993, p. 98), discrimination affects minorities by 'lowering the probability of black [minority] entry into white [advantaged] neighborhoods'. Even if having less choices on the housing market, minority households can still experience equal adverse effects of pollution at their place of residence, and thus exhibit similar effects of pollution on the probability of moving. Though the anticipation of discrimination could still play a role, the discrimination thesis is likely to play a minor role in explaining selective outmigration processes than in selective in-migration processes. As a consequence, the minority gap in out-migration should be less pronounced than the minority gap in in-migration. Note that this is supported by the descriptive finding that minorities are more mobile in general (e.g. Crowder, South, \& Chavez, 2006; Ihrke \& Faber, 2012) but achieve lower migrational returns, and thus end up in more disadvantaged neighbourhoods when relocating (e.g. Crowder \& South, 2005; South, Huang, Spring, \& Crowder, 2016).

A third explanation for different moving trajectories of minority households are residential preferences. Minorities might choose other places of residence because of similarity preferences (e.g. Collins, Grineski, Chakraborty, Montgomery, \& Hernandez, 2015; Kim, Campbell, \& Eckerd, 2014), or because different 'everyday routines' lead to other choice sets for housing (Krysan \& Crowder, 2017). Based on a comparison of German cities, Rüttenauer (2019) hypothesises that minorities experience higher levels of pollution and lower pollution-returns in migration because minorities tend to live and relocate within metropolitan core areas (see also Logan, Zhang, \& Alba, 2002), in which pollution levels are generally higher. However, as with the previous explanation, residential preferences and different search strategies predict different pollution levels at the place of destination in a migration process, and are thus more suited to explain selective 
in-migration. After deciding to relocate, minority households make their choices based on similarity preferences, racialized experiences, or tend to stay in more central areas, leading to lower moving returns and higher environmental burdens at the place of destination. Still, this does not predict that minorities feel less affected by environmental pollution at their current place of residence, and thus does not predict that minorities exhibit lower effects of pollution on the probability of leaving.

So far, we know surprisingly little about the different stages of the selective migration process. As already mentioned, studies based on spatially aggregated data offer ambiguous results, and are not suitable for disentangling selective inand out-migration stages (e.g. Banzhaf et al., 2019; Depro et al., 2015). Besides that, a wide range of studies on hedonic house price models have emphasized the role of selective migration process. Still, they are mainly interested in the "willingness to pay' for amenities, which reflects economic but not racial or ethnic disparities, and the studies rarely aim to separate the stages of migration. Moreover, results offer no clear picture on the question of whether selectively 'fleeing the nuisance' contributes to price effects or demographic changes around unwanted amenities (e.g. Cameron, Crawford, \& McConnaha Ian T., 2012; Depro et al., 2015; Noonan, Krupka, \& Baden, 2007).

In contrast, the literature on neighbourhood attainment has a stronger focus on individual level panel data to investigate the more general processes of achieving residency in affluent neighbourhoods (e.g. Leibbrand \& Crowder, 2018). Though this focus on individual data allows to observe actual migration patterns, most studies do not distinguish between processes that prevent out-migration of minorities and processes determining the destination of minorities. The ability of minorities to 'escape' disadvantaged neighbourhoods in most instances refers to the transition from disadvantaged to mainstream / advantaged neighbourhoods, which constitutes a combination of in- and out-migration patterns. For instance, Crowder and South (2005); South and Crowder (1997) demonstrate that Black households are less likely to move from poor to nonpoor neighbourhoods, and Quillian (2015) shows that Black households sort into neighbourhoods with higher poverty rates and proportions of Black inhabitants. However, as the reference category also includes households moving from poor to poor (high minority to high minority, respectively) neighbourhoods, we cannot infer if Black households are less likely to move out of their current place of residence - independent of where they end up. The gross migration rates of households originating in poor neighbourhoods, in fact, point towards similar mobility rates of the minority groups (South \& Crowder, 1997).

The literature mentioned above provides only suggestive evidence for the hypothesis that the out-migration process is less selective based on minority status 
than the in-migration process. Best to our knowledge, Crowder and Downey (2010) provide the only direct test of the selective out-migration thesis regarding environmental pollution. Based on the US Panel Study of Income Dynamics, their results indicate that 1 ) the effect of pollution on the probability of leaving the neighbourhood is weak in general, and 2) no significant racial differences remain once the models account for economic and demographic characteristics (especially age). This finding supports the idea that discrimination and preferences play a minor role in the out-migration process, thereby elevating the importance of socio-economic characteristics. The study by Crowder and Downey (2010), however, does not test if the effect of pollution on out-migration depends on income.

In sum, when differentiating between in- and out-migration processes, theory predicts that in- and out-migration processes are selective based on income, as the same economic argument applies to both parts the selective migration process. In contrast, differential moving trajectories based on minority status should be more pronounced in the course of in-migration, as discrimination on the housing market and different residential preferences or search strategies are likely to be less influential for out-migration decisions. Thus, the strongest theoretical reason for differences in the out-migration processes between majority and minority households is based on economic constraints.

\section{Analytical strategy}

To test our hypotheses, we rely on data of the German Socio-Economic Panel (SOEP, v33.1) at the household level (Goebel et al., 2019). The SOEP is longitudinal panel study of German households, representative of the German population, and comprises annual information on nearly 15,000 households since 1984. In the German SOEP, immigrant-minorities have been oversampled, which constitutes a crucial advantage for our analysis. We use the waves 1986, 1994, 1999, 2004, 2009, and 2014 in which respondents were asked to complete an extended household questionnaire containing our main explanatory variable.

Amongst others, the household questionnaire contains a question on the subjective impairment through air pollution, which is very well suited to test our research question. When relying on objective measures of pollution, we need to make the implicit assumption that households are aware about the actual pollution level at their place of residence (Collins et al., 2015; Depro et al., 2015). For instance, we may not observe reactions to changes in objective pollution because people are not aware about these marginal changes. In contrast, changes in the measure of perceived pollution indicate that a visible change in quality has taken place. This provides a more direct test of whether perceivable environmen- 
tal pollution constitutes a reason to leave an area, and if its impact on moving depends on income and minority status. To account for resulting problems of diverging subjective evaluations, we rule out potential time-constant differences in sensitivity to air pollution levels by relying on within-household estimates.

\subsection{Variables}

Our analysis investigates the effect of perceived environmental pollution on the probability of moving out. As mentioned above, the main explanatory variable is the self rating of the impairment though air pollution. Respondents where asked to rate on a 5-point scale: 'To what extent do you feel affected by the following environmental factors in this neighborhood? Air pollution' (1 - not at all, $5-$ extremely). The dependent variable is a binary indicator of out-migration, taking the value 1 if households move between the observation periods. We construct this indicator by using the full SOEP sample including all waves to observe relocation occurring between the wave intervals of the final sample. For instance, if a household moved between 2004 and 2009, this is indicated by our moving variable in 2009. As a consequence, we use the impairment though air pollution as time lag $(t-1)$, which assesses if changes in impairment in 2004 triggered migration between 2004 and 2009, thereby indicating if the impairment through air pollution influences the moving probability in the following period. Because of this time-lag structure, we also include the period 2014-2016 to construct our outcome variable of relocation, which allows us to include an additional wave. We account for diverging moving probabilities based on different lengths of the time intervals by including period dummies.

To scrutinize differential effects of air pollution on the likelihood of moving we include an interaction of the pollution rating with 1) the monthly household's equivalence income, and 2) minority status. The household's equivalence income is constructed as the household's total net income divided by the square root of the number of household members. For minority background, we further distinguish between first generation immigrants who immigrated themselves to Germany, and second generation immigrants who were born in Germany but have at least one parent who immigrated to Germany. Third generation immigrants and their descendants are define as 'native' German. This distinction is important given that previous results on selective in-migration find distinct patterns between first and second generation immigrants (Best \& Rüttenauer, 2018). While first generation immigrations show pronounced disadvantages in moving returns, second generation immigrations seem to be very similar to the native German population. This definition of minority households also includes immigrants originating from wealthy Western countries. However, excluding this 
Table 1. Summary Statistics

\begin{tabular}{|c|c|c|c|c|c|c|}
\hline \multirow[t]{2}{*}{ Variable } & \multicolumn{2}{|c|}{ Native German } & \multicolumn{2}{|c|}{ 1st gen. minority } & \multicolumn{2}{|c|}{ 2nd gen. minority } \\
\hline & Mean & SD within & Mean & SD within & Mean & SD within \\
\hline Move within two periods & 0.378 & 0.456 & 0.393 & 0.462 & 0.411 & 0.466 \\
\hline Impairment air pollution & 1.858 & 0.658 & 1.932 & 0.662 & 1.897 & 0.663 \\
\hline Household income (in t) & 1.59 & 0.564 & 1.220 & 0.410 & 1.685 & 0.597 \\
\hline Age & 51.362 & 5.539 & 51.748 & 5.380 & 42.912 & 5.133 \\
\hline Child(ren) in household & 0.447 & 0.314 & 0.634 & 0.272 & 0.485 & 0.310 \\
\hline Partner in household & 0.685 & 0.276 & 0.797 & 0.194 & 0.696 & 0.273 \\
\hline Distance to city centre & 3.099 & 0.782 & 3.013 & 0.730 & 2.730 & 0.716 \\
\hline Condition of flat/house & 3.603 & 0.434 & 3.584 & 0.450 & 3.643 & 0.376 \\
\hline $\mathrm{N}$ households & \multicolumn{2}{|c|}{3097} & \multicolumn{2}{|r|}{537} & \multicolumn{2}{|r|}{156} \\
\hline $\mathrm{N}$ & \multicolumn{2}{|c|}{10910} & \multicolumn{2}{|c|}{1805} & \multicolumn{2}{|r|}{526} \\
\hline
\end{tabular}

sub-population from the analysis does not influence the results due to a relative small number of cases. To construct the migration background for a household, we used the information given by the household head. This is a conservative approach, as we would under-estimate minority effects if other native German household members would act on the housing market.

Moreover, we include two different sets of control variables. As basic controls we include year dummies and age. To overcome the age-period problem in within models and simultaneously allow for non-linearities, age is included as a set of 5 -year interval dummies. In the set of additional controls, we add further timevarying variables: child(ren) living in the household $(0,1)$, (marriage) partner living in the household $(0,1)$, distance to nearest city centre $(1-$ central, 6 $>60 \mathrm{~km}$; dichotomised), and housing conditions (1 - condemned, 4 - in good condition; dichotomised). All those variables may simultaneously influence the household's income as well as the moving probability. Note that we intentionally do not control for home ownership, as this is likely to be a consequence of income, and thus constitutes an indirect path of the income effect rather than a confounding mechanism (e.g. Clark, Deurloo, \& Dieleman, 1997).

Because of the unbalanced panel structure, we restricted the sample to households who participated in at least two waves, and reported at least one period of stationary living situation and one period of relocation (for the explanation see the following subsection). This leads to a final sample of 13,247 observations and 3,792 households. We performed additional robustness checks in Table B2 and the Supplement which include the full sample of households, including those without a change in migration (see also Discussion section). Summary statistics can be found in Table 1. On average, 38.1\% of our observations exhibit a move, which corresponds to roughly $7.4 \%$ per year, as our observation periods are based on 5.17 year intervals on average. The mean impairment though air pollution lies around 1.9 for all minority groups, and exhibits sufficient within-household variation over time (within standard deviation of nearly 0.7 ). 


\section{2. $\quad$ Method}

Unobservable characteristics are likely to influence our explanatory variables as well as our outcome. For instance, active and outgoing individuals might indicate higher levels of pollution, and at the same time have higher earnings and be more residentially mobile. This provides a strong motivation for within-household estimators, which test if within-household changes in air quality and income coincide with changes in the likelihood of moving within the following time period. This effect can only be calculated for households who actually remained at their place of living in at least one period but also moved in at least one period, as all other observation do not contain any relevant within variation (Baltagi, 2013; Wooldridge, 2010). Thus, we restrict the final sample to those households who exhibit some variation due to different moving behaviour in different periods.

An obvious choice of model specification in this framework would be the fixed-effects (FE) logit model (e.g. Allison, 2009; Wooldridge, 2010), which controls for household-specific time-constant heterogeneity. However, FE logit models do not allow to estimate average marginal effects (AMEs; Baltagi, 2013; Wooldridge, 2010), as this requires actual values for the unknown individual effects (Wooldridge, 2010, p. 622). Still, estimating AMEs is crucial in our case as we need to interpret interaction effects in non-linear models (Best \& Wolf, 2015; Breen, Karlson, \& Holm, 2018; Long \& Mustillo, 2018; Mize, 2019). Following Wooldridge (2010), we thus calculate the AMEs for the within-household estimator by estimating Chamberlain's correlated random effects (CRE) probit models, which include the person-specific means of the covariates as additional regressors (Chamberlain, 1982; Mundlak, 1978; Wooldridge, 2010). Identical to FE models, the CRE gives us an estimate of the within effect. Moreover, the CRE probit has the advantage that we replace the unknown individual effects by the household-specific means to compute AMEs. Formally, the model is given by

$$
\mathrm{P}\left(y_{i t}=1 \mid \boldsymbol{x}_{i}\right)=\boldsymbol{\Phi}\left(\psi+\boldsymbol{x}_{i t} \boldsymbol{\beta}+\overline{\boldsymbol{x}}_{i} \boldsymbol{\xi}\right),
$$

using the decomposition of the individual-specific effects $c_{i}=\psi+\overline{\boldsymbol{x}}_{i} \boldsymbol{\xi}+a_{i}$, where $\boldsymbol{\Phi}(\cdot)$ is a standard normal cumulative distribution function, $\overline{\boldsymbol{x}}_{i}$ are the individual-specific means of $\boldsymbol{x}_{i t}$, and $\psi, \boldsymbol{\beta}, \boldsymbol{\xi}$ are the parameter vectors. We are only interested in the coefficient vector $\boldsymbol{\beta}$, representing the within-household effects due to the inclusion of household-specific means (Mundlak, 1978). Vector $\boldsymbol{\beta}$ provides a consistent estimate of the within / FE effect under assumption $c_{i} \mid \boldsymbol{x}_{i} \sim \operatorname{Normal}\left(\psi+\overline{\boldsymbol{x}}_{i} \boldsymbol{\xi}, \sigma_{a}^{2}\right)$, i.e the conditional variance of the unobserved household-specific effect $c_{i}$ is independent of $\boldsymbol{x}_{i}$. As the CRE includes estimates of the unobserved effect for the respective covariates, we can obtain predicted 
probabilities and AMEs for the within effects, which we cannot in a conventional FE logit model. Obviously, we still need the strict exogeneity assumption conditional on the individual effects to hold: $\mathrm{D}\left(y_{i t} \mid \boldsymbol{x}_{i}, c_{i}\right)=\mathrm{D}\left(y_{i t} \mid \boldsymbol{x}_{i t}, c_{i}\right)$. Thus, we allow $\boldsymbol{x}_{i}$ to be correlated with levels in $\boldsymbol{y}_{i}$, but not with idiosyncratic changes in $y_{i t}$.

In the following section, we interpret the AMEs of the CRE probit models. These AMEs indicate how within-household changes in the impairment though air pollution correlate with change in the likelihood of out-migration. Based on the interactions, we furthermore investigate if this effect of perceived air pollution depends on variations in the household's income, or respectively, how it differs between native German and immigrant minority households. We will mainly refer to graphical representations of the AMEs relevant for our research question. The respective coefficients can be found in Table A1 of the Appendix.

\section{Results}

In the first two models (M1 and M2), we test if the effect of pollution on outmigration depends on income. The following two models analyse differential migration responses of minority groups (M3 and M4). In both cases, we have one model containing the basic controls age and year, and a second specification with further controls, namely children in the household, living with partner, distance to city centre and housing condition. In a final step, we combine income and minority interaction effects in a common model (M5) to examine whether income helps to explain the minority gap.

We start with the question of whether the effect of air pollution on the moving probability depends on the household's income. Models M1 and M2 include an interaction effect between the impairment through air pollution and the household equivalence income. As can be seen in Figure 1 (M1), the perceived air pollution is positively associated with the probability of moving at the average income level, thereby documenting the tendency of households to escape pollution. However, more interestingly, the average marginal effect of air pollution on the probability of out-migration depends on income. When keeping income constant at the average, a one unit increase in air pollution increases the probability of out-migration by $5.8 \%$-points. This effect increases to $7.1 \%$-points if the household's income increases by a within standard deviation (or 547 EUR). The difference between both AMEs of $1.4 \%$-points is highly significant according to a Wald test $(\mathrm{p}=0.002)$, which confirms that households selectively leave polluted areas when their income increases.

When adding further demographic and housing related controls in M2, results change only slightly. As shown in Figure 2, we only see a change in the effect's 


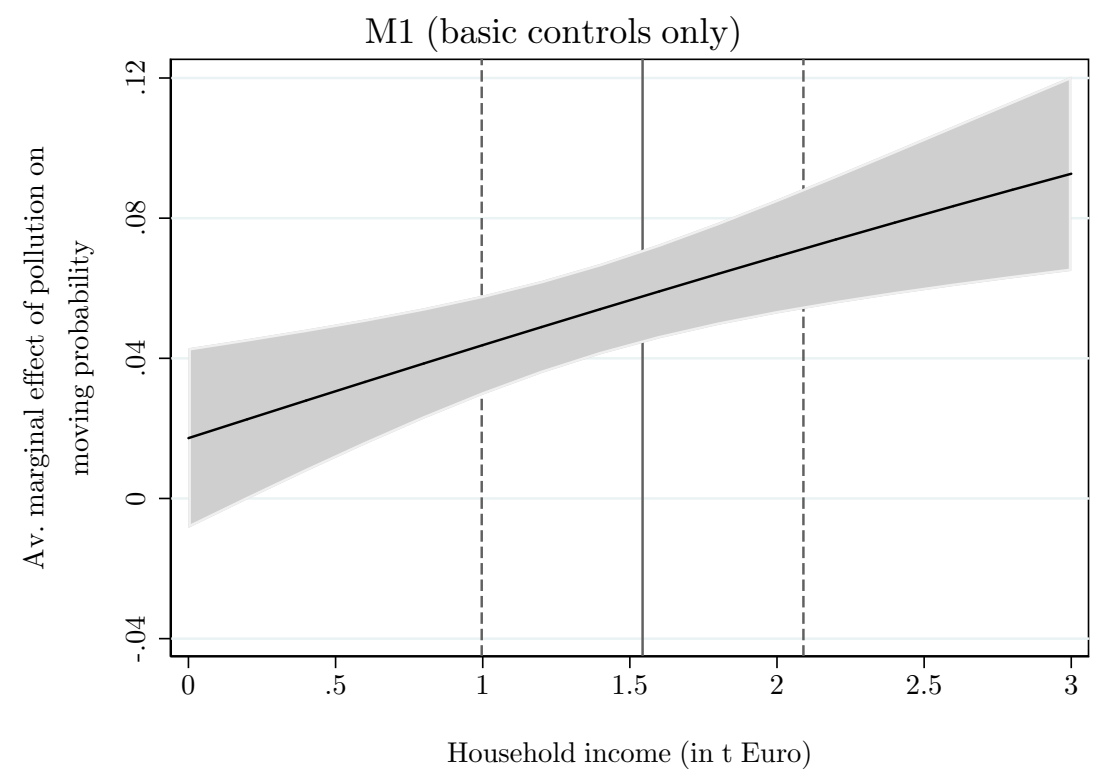

Figure 1. AME of air pollution on the likelihood of moving out conditional on income (M1, Table A1) with 95\% CI. Dashed lines mark +/- one within SD from the mean.

intercept, meaning that for our selected range of values, the effect of changes in perceived pollution on the probability of out-migration decreases net of other socio-demographic changes. However, the selectivity (or interaction) based on income becomes slightly stronger. In model M2, a one standard deviation increase in income from the mean is associated with a $1.6 \%$-point higher marginal effect (4.1\%-points vs. $5.6 \%$-points), which is again highly significant ( $\mathrm{p}<=$ 0.001). This means that air pollution exerts a higher effect on the probability of out-migration when a household's income increases even if we control for other life-cycle events and the quality of housing. In sum, the models indicate that income indeed plays a role for 'fleeing the nuisance': selective out-migration based on income contributes to environmental inequality. In terms of magnitude, the selectivity is moderately strong: given the baseline probability of $38.1 \%$, a change in perceived pollution around the mean amplifies the probability of moving by $10.8 \%$ at a constant income, and by $14.7 \%$ after a one standard deviation increase in income.

To assess the selectivity of the out-migration process based on minority status, Figure 3 depicts the marginal effects of air pollution on the probability of outmigration for native German, first and second generation immigrant households (M3 - M5). When looking at the basic model M3, we can see that air pollution has a significant positive effect on the probability of out-migration for German households: an increase in air pollution by one unit increases the probability of out-migration by 5.8\%-points. Similarly, the probability of out-migration in- 


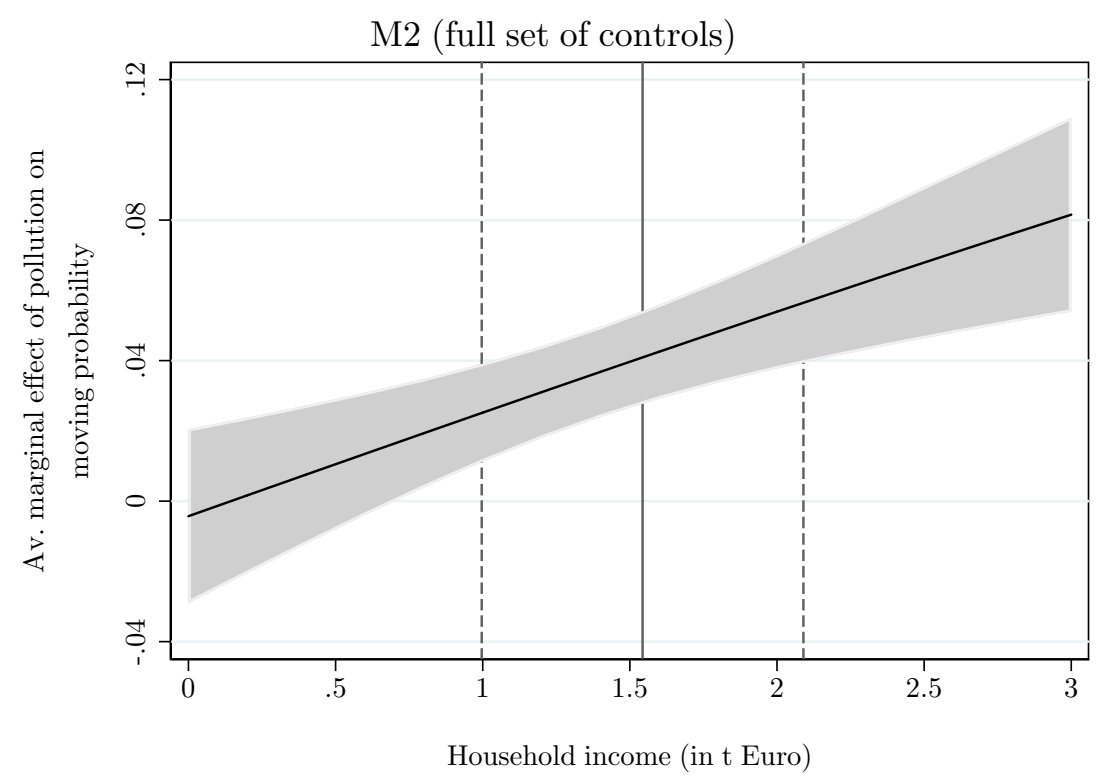

Figure 2. AME of air pollution on the likelihood of moving out conditional on income (M2, Table A1) with 95\% CI. Dashed lines mark +/- one within SD from the mean.

creases by $7.6 \%$-points for second generation immigrants. In contrast, first generation immigrants exhibit a marginal effect of only $1.7 \%$-points, which is not significantly different from zero. Furthermore, the difference between native German households and first generation immigrants is significant at the $5 \%$ level (p $=0.024)$. Thus, when only taking year and age into account, results indicate that first generation minorities are significantly less likely to move when perceived air pollution increases. When adding additional controls (M4), the AMEs of air pollution become slightly weaker, but the difference between native German and first generation immigrants is nearly unaffected (4.0\%-points vs. 0.5\%-points), and the difference in AMEs based on cluster robust standard errors is at the border of the $5 \%$ significance level $(\mathrm{p}=0.056)$. This means that native Germans are still more likely to escape polluted areas than first generation immigrants when comparing households in a similar socio-demographic situation, though the difference becomes imprecise. Moving behaviour of second generation immigrants, in contrast, does not differ from the behaviour of native German households with regard to pollution.

Finally, we want to know if the differences between minorities and native Germans are (at least partly) the result of differences in economic resources. Model M5 in Figure 3 shows the marginal effects for the three groups after controlling for income and the income-pollution interaction. Though controlling for income has little effect on the AMEs of native German and second generation immigrant households, we see a change for first generation immigrants: if they had the same 


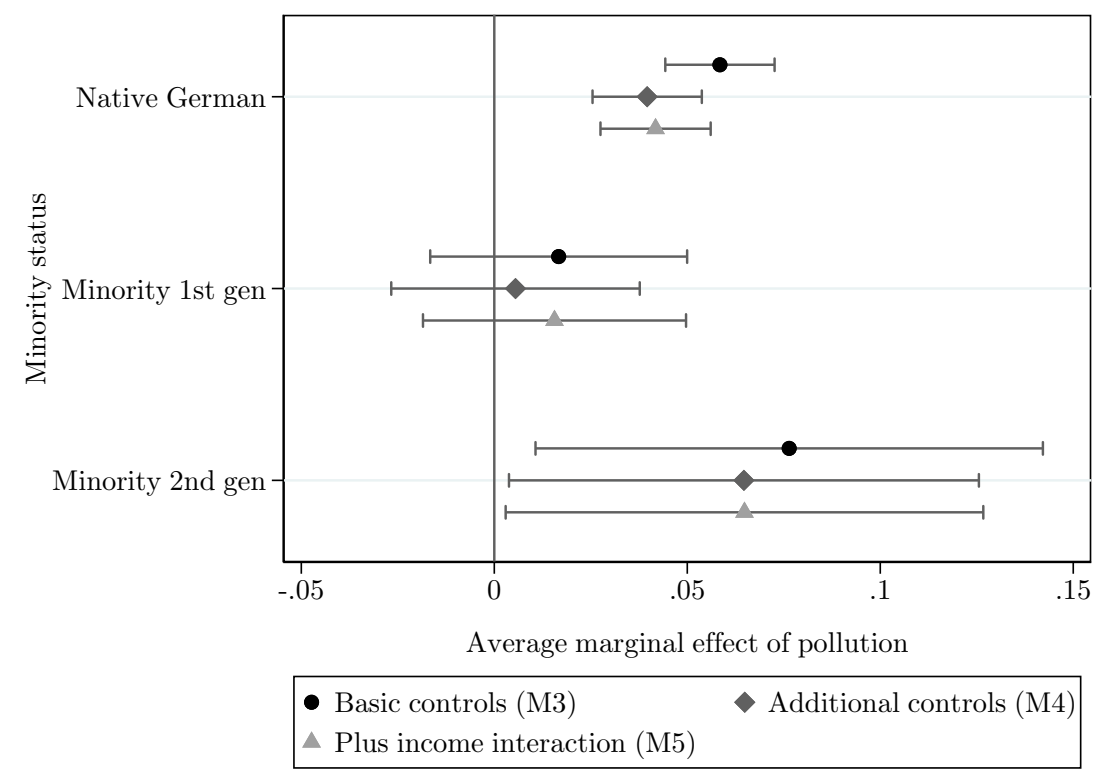

Figure 3. AME of air pollution on the likelihood of moving out conditional on minority status (M3-M5, Table A1) with $95 \%$ CI.

economic resources, an increase in impairment through air pollution would increase the probability of out-migration by $1.6 \%$-points, on average. This is still lower than the effect experienced by native German households (4.2\%-points). Yet, the difference between native German households and first generation immigrants is not statistically significant (2.6\%-points, $\mathrm{p}=0.163)$, and much smaller than the difference found in model M4. Though the difference in differences between M4 and M5 is not statistically significant, the change seems substantial in magnitude. Once we control for selective migration behaviour based on income, the disadvantage of first generation immigrants is reduced by more than $20 \%$ (compared to M4), and we cannot reject the null-hypothesis of identical AMEs of air pollution on the probability of out-migration for native German households and (first and second generation) minority households.

To further test if these conclusions differ depending on the income level, we estimated an additional model including an interaction of the minority status with income and the air pollution-income interaction (three-way interaction). Note that we do not show the results in Table A1 because the three-way interactions are barely interpretable in a non graphical framework. Figure 4 depicts the result of this fully interacted model graphically, which illustrates two important findings. First, across the entire span of realistic income values, we do not observe a significant difference between native Germans and first generation immigrant households. The differences in AMEs between Germans and immigrant households are most pronounced at 800 and 1,000 EUR with 3.0 and $2.8 \%$-points. 


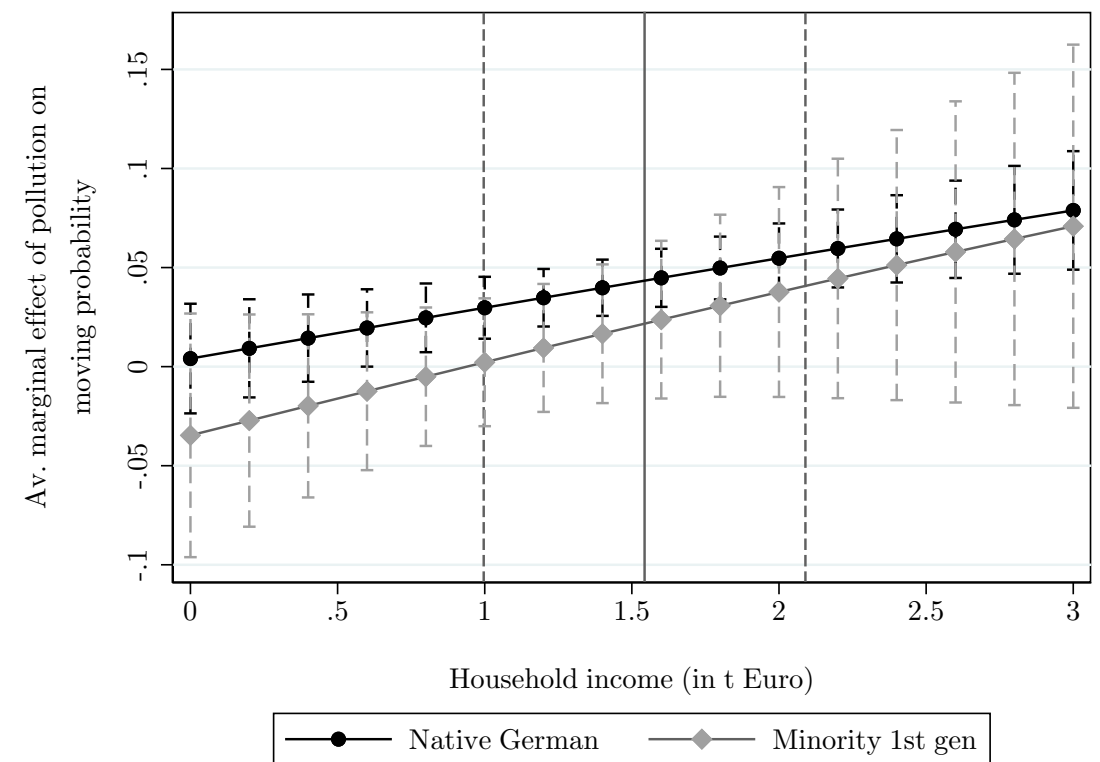

Figure 4. AME of air pollution on the likelihood of moving out conditional on income (not shown in Tables) with $95 \%$ CI. Short-dashed lines mark +/- one within SD from the mean.

Still, the differences are not statistically significant $(\mathrm{p}>=0.130)$. Second, there are no substantial group-differences in the income-selectivity of the air pollution effect. Though the slope of the air pollution effect across the income span is a little steeper for immigrant households, second differences in AMEs are far from significant. Accordingly, income plays a similar role for native German and first generation immigrants in escaping polluted areas.

\section{Discussion}

Our findings indicate that income plays a role for escaping perceived air pollution, and that first generation minorities are less likely to move because of increases in pollution. However, a relatively large proportion of the minority effect can be attributed to the lack of sufficient economic resources. This finding is in line with results from the US by Crowder and Downey (2010), who do not find minority differences in the out-migration effect of pollution when controlling for socio-demographic characteristics. The selectivity of income, in contrast, remains stable across all our models. Thus, if all households would have the same income trajectories, we would not observe a statistically significant selectivity based on minority status. This conforms to the idea that socio-economic differences play an important role in explaining out-migration disadvantages of minorities.

At first glance, it is surprising that we find a robust income effect, and minority disadvantages which are sensitive to model specification. Analysing selective 
in-migration using the same data, Best and Rüttenauer (2018) identified a robust and strong minority effect, but only marginal interactions with income. Furthermore, the minority disadvantage in the environmental returns due to migration did not change at all after controlling for income. Analysing selective out-migration, in contrast, we find robust income differentials in the effect of pollution on the moving probability, but sensitive minority disadvantages, which can be explained to a substantial extent by economic differences. This finding also conforms to results from the US. When looking at selective in-migration only, income does a rather poor job in explaining racial differences (Crowder \& Downey, 2010). In contrast, when looking at migration trajectories pooling out- and in-migration processes, it explains a relatively large proportion of the racial gap (Pais et al., 2014). As we have outlined theoretically, this result is plausible because the argument of selective reactions to environmental pollution rests upon the assumption of differences in the willingness or ability to pay for environmental quality. Other non-economic explanations for minority disadvantages - discriminatory practices of housing agents or destination-preferences are mainly relevant for in-migration stage and are likely to play a minor role in out-migration decisions. Nevertheless, once a household has decided to move, different locational preferences or barriers due to discrimination against minorities may become more important than income constraints. This would result in an income-dependent effect for the out-migration process, but an incomeindependent minority effect for the in-migration process.

Certainly, our results come with several limitations. First, given the long time period, we are not able to enrich data with consistent objective measures of pollution. Nevertheless, as we have argued earlier, relying on subjective measures provides a direct test of selective reactions to perceived pollution changes and this is an important condition for any effect of objective air pollution. Second, the number of cases gets relatively small when separating between immigrant groups. Thus, we have not enough power to investigate differences according to the country of origin, which masks potential heterogeneity among immigrants (Best \& Rüttenauer, 2018). Third, we can not fully rule out confounding by unobserved time-varying shocks. For instance, general life-course changes and family-planning might be connected to moves into rural (less polluted) areas and coincide with increases in income (Kley, 2011). Though we try to account for this confounding by controlling for age groups, child(ren) in the household, and distance to the next city centre, these are only rough proxies of very heterogeneous life-course trajectories. Nevertheless, one could even argue that these life-course changes connected to income variation and internal migration are part of the environmental inequality process, though they are driven by other coinciding decisions rather than completely exogenous income 'shocks' itself. 
Moreover, the results are fully supported by additional robustness checks. First, relations between coefficients in FE logit models (Table B1) support the storyline above. Second, linear fixed-effects probability models (see Table B2) derive at the same conclusions, and confirm the drop in effect size of more than $20 \%$ when controlling for income. Third, the AMEs of CRE probit based on the full sample including households without any within-variance on migration $(\mathrm{N}=$ 28,408; N households $=8,867$ ) fully support the results presented here, though obviously total effect sizes are dragged towards zero, as the additional observations will naturally have a zero-effect on all covariates (see Online Supplement S1). Fourth, also when weighting the sample by inverse probability of staying weights, results closely resemble those presented above (see Online Supplement S2).

\section{Conclusions}

In this study, we use household-level panel data and within estimators to investigate the selective out-migration process of environmental inequality. We analyse if the effect of perceived environmental pollution on the probability of moving changes with income and whether the effect differs between minority groups. We find that the subjective perception of air pollution increases the likelihood of moving, and that this effect increases with income: households experiencing an increasing income are more likely to escape polluted areas than households with a constant or declining income. Interestingly, the differences between native Germans and first generation minority households are sensitive to the model specification, and decline by more than $20 \%$ once we control for heterogeneous income effects. This indicates that economic constrains play an important role in selective out-migration processes according to minority status.

Theoretically, we argue that selective out-migration and selective in-migration contribute to environmental inequality in different ways. When splitting apart the causal pathway of selective migration, it appears that some of the common explanations for minority disadvantages are less important for out-migration processes. Discrimination on the housing market as well as residential preferences or racialized search strategies are well suited to explain differential in-migration processes, but seem (at least) less important for the stage of fleeing from environmental pollution. Even if minority households experience discrimination on the housing market and value other socio-demographic or urban characteristics, they might still experience similar negative effects of air pollution on the satisfaction with their place of residence, and thus exhibit a similar effect on the probability of leaving. A remaining explanation for minority differences is the unequal endowment with economic resources. 
This strand of reasoning is fully supported by our empirical results: for the stage of out-migration, income is connected to how pollution changes the likelihood of moving, and also explains a relatively large part of the minority disadvantage. As indicated by previous studies, the importance of these dimensions however changes when looking at the in-migration stage of the sorting process: for pollution at the place of destination, minority background seems to be a stronger predictor than income (Best \& Rüttenauer, 2018; Crowder \& Downey, 2010). This also provides a straightforward answer to the questions of what matters more 'race or class': both matters, but at different stages of the sorting process. For instance, reducing economic inequality among ethnic groups may not have a substantial impact on the decision of destination. However, it can still help to provide equal opportunities for escaping environmental disamenities.

Obviously, our theoretical argument needs further investigation based on different datasets and different contexts. Still, the results might have implications beyond environmental inequality, and also add new insights to the broader neighbourhood attainment literature (e.g. Crowder \& South, 2005; Quillian, 2012). If our findings hold for different neighbourhood (dis)amenities, our theoretical assumption can offer an explanation for mixed findings on whether racial sorting processes result from income differences. Minority households might not be able to escape from disadvantaged neighbourhoods because they have lower economic resources. However, the sorting into disadvantaged neighbourhoods is based on mechanisms independent of income, like residential preferences, different experiences and search strategies, or housing discrimination (Krysan \& Crowder, 2017). Thus, it seems promising to have a more detailed look into the different stages of neighbourhood attainment, and to separate the stages of selective outand in-migration in future research.

In sum, the results of this study highlight the importance of clearly distinguishing between different stages in the pathway of selective sorting and environmental inequality. By separating the different stages and using micro-level panel data to scrutinize migration trajectories, we show that different mechanisms operate between fleeing disadvantaged neighbourhoods and sorting into new destinations. Further research may profit by taking these fine grained steps into account, and shed more light on the complex processes leading to a severe dimension of social inequality. 


\section{References}

Allison, Paul David. (2009). Fixed Effects Regression Models (Vol. 160). Los Angeles: Sage.

Ard, Kerry. (2015). Trends in Exposure to Industrial Air Toxins for Different Racial and Socioeconomic Groups: A Spatial and Temporal Examination of Environmental Inequality in the U.S. from 1995 to 2004. Social Science Research, 53, 375-390.

Ash, Michael, \& Boyce, James K. (2018). Racial Disparities in Pollution Exposure and Employment at US Industrial Facilities. Proceedings of the National Academy of Sciences of the United States of America, 115(42), 10636-10641.

Auspurg, Katrin, Schneck, Andreas, \& Hinz, Thomas. (2019). Closed Doors Everywhere? A Meta-Analysis of Field Experiments on Ethnic Discrimination in Rental Housing Markets. Journal of Ethnic and Migration Studies, 45(1), 95-114.

Baltagi, Badi Hani. (2013). Econometric Analysis of Panel Data (5. ed.). Chichester: Wiley.

Banzhaf, H. Spencer, Ma, Lala, \& Timmins, Christopher. (2019). Environmental Justice: Establishing Causal Relationships. Annual Review of Resource Economics, 11(1), 377-398.

Banzhaf, H. Spencer, Sidon, Joshua, \& Walsh, Randall P. (2012). Environmental Gentrification and Discrimination. In H. Spencer Banzhaf (Ed.), The Political Economy of Environmental Justice (pp. 75-111). Palo Alto: Stanford Univ. Press.

Banzhaf, H. Spencer, \& Walsh, Randall P. (2008). Do People Vote with Their Feet? An Empirical Test of Tiebout's Mechanism. American Economic Review, 98(3), 843-863.

Banzhaf, H. Spencer, \& Walsh, Randall P. (2013). Segregation and Tiebout Sorting: The Link between Place-Based Investments and Neighborhood Tipping. Journal of Urban Economics, 74, 83-98.

Bayer, Patrick, Keohane, Nathaniel, \& Timmins, Christopher. (2009). Migration and Hedonic Valuation: The Case of Air Quality. Journal of Environmental Economics and Management, 58(1), 1-14.

Been, Vicki, \& Gupta, Francis. (1997). Coming to the Nuisance or Going to the Barrios - A Longitudinal Analysis of Environmental Justice Claims. Ecology Law Quarterly, 24 (1), 1-56.

Best, Henning, \& Rüttenauer, Tobias. (2018). How Selective Migration Shapes Environmental Inequality in Germany: Evidence from Micro-Level Panel Data. European Sociological Review, 34(1), 52-63. 
Best, Henning, \& Wolf, Christof. (2015). Logistic Regression. In Henning Best \& Christof Wolf (Eds.), The Sage Handbook of Regression Analysis and Causal Inference (pp. 153-171). Los Angeles: Sage.

Breen, Richard, Karlson, Kristian Bernt, \& Holm, Anders. (2018). Interpreting and Understanding Logits, Probits, and Other Nonlinear Probability Models. Annual Review of Sociology, 44 (1), 39-54.

Bullard, Robert D. (1990). Dumping in Dixie: Race, Class, and Environmental Quality. Boulder: Westview.

Cameron, Trudy Ann, Crawford, Graham D., \& McConnaha Ian T. (2012). Superfund Taint and Neighborhood Change. In H. Spencer Banzhaf (Ed.), The Political Economy of Environmental Justice (pp. 137-169). Palo Alto: Stanford Univ. Press.

Chamberlain, Gary. (1982). Multivariate Regression Models for Panel Data. Journal of Econometrics, 18(1), 5-46.

Clark, William A. V., \& Coulter, Rory. (2015). Who Wants to Move? The Role of Neighbourhood Change. Environment and Planning A, 47(12), 2683-2709.

Clark, William A. V., Deurloo, Marinus C., \& Dieleman, François M. (1997). Entry to Home-ownership in Germany: Some Comparisons with the United States. Urban Studies, 34(1), 7-19.

Collins, Timothy W., Grineski, Sara E., Chakraborty, Jayajit, Montgomery, Marilyn C., \& Hernandez, Maricarmen. (2015). Downscaling Environmental Justice Analysis: Determinants of Household-Level Hazardous Air Pollutant Exposure in Greater Houston. Annals of the Association of American Geographers, 105(4), 684-703.

Crowder, Kyle, \& Downey, Liam. (2010). Inter-Neighborhood Migration, Race, and Environmental Hazards: Modeling Micro-Level Processes of Environmental Inequality. American Journal of Sociology, 115(4), 1110-1149.

Crowder, Kyle, \& South, Scott J. (2005). Race, Class, and Changing Patterns of Migration between Poor and Nonpoor Neighborhoods. American Journal of Sociology, 110(6), 1715-1763.

Crowder, Kyle, South, Scott J., \& Chavez, Erick. (2006). Wealth, Race, and Inter-Neighborhood Migration. American Sociological Review, 71 (1), 72-94.

Depro, Brooks, Timmins, Christopher, \& O'Neil, Maggie. (2015). White Flight and Coming to the Nuisance: Can Residential Mobility Explain Environmental Injustice? Journal of the Association of Environmental and Resource Economists, 2(3), 439-468.

Diekmann, Andreas, \& Meyer, Reto. (2010). Demokratischer Smog? Eine empirische Untersuchung zum Zusammenhang zwischen Sozialschicht und Umweltbelastungen. Kölner Zeitschrift für Soziologie und Sozialpsychologie, 
62(3), 437-457.

Downey, Liam. (2005). The Unintended Significance of Race: Environmental Racial Inequality in Detroit. Social Forces, 83(3), 971-1007.

Ewens, Michael, Tomlin, Bryan, \& Wang, Liang Choon. (2014). Statistical Discrimination or Prejudice? A Large Sample Field Experiment. Review of Economics and Statistics, 96(1), 119-134.

Gamper-Rabindran, Shanti, \& Timmins, Christopher. (2011). Hazardous Waste Cleanup, Neighborhood Gentrification, and Environmental Justice: Evidence from Restricted Access Census Block Data. American Economic Review, $101(3), 620-624$.

Glatter-Götz, Helene, Mohai, Paul, Haas, Willi, \& Plutzar, Christoph. (2019). Environmental Inequality in Austria: Do Inhabitants' Socioeconomic Characteristics Differ Depending on Their Proximity to Industrial Polluters? Environmental Research Letters, 14(7), 074007.

Goebel, Jan, Grabka, Markus M., Liebig, Stefan, Kroh, Martin, Richter, David, Schröder, Carsten, \& Schupp, Jürgen. (2019). The German Socio-Economic Panel (SOEP). Jahrbücher für Nationalökonomie und Statistik, 239(2), 345360 .

Hamilton, James T. (1995). Testing for Environmental Racism: Prejudice, Profits, Political Power? Journal of Policy Analysis and Management, 14(1), $107-132$.

Ihrke, David K., \& Faber, Carol S. (2012). Geographical Mobility: 2005 to 2010. Retrieved 2017-10-02, from www.census.gov/prod/2012pubs/p20-567.pdf

Kim, Yushim, Campbell, Heather, \& Eckerd, Adam. (2014). Residential Choice Constraints and Environmental Justice. Social Science Quarterly, 95(1), 4056 .

Kley, Stefanie. (2011). Explaining the Stages of Migration within a Life-course Framework. European Sociological Review, 27(4), 469-486.

Krysan, Maria, \& Crowder, Kyle. (2017). Cycle of Segregation: Social Processes and Residential Stratification. Chicago: Russell Sage Foundation.

Landrigan, Philip J., Fuller, Richard, Acosta, Nereus J. R., Adeyi, Olusoji, Arnold, Robert, Basu, Niladri, ... Zhong, Ma (2018). The Lancet Commission on Pollution and Health. The Lancet, 391 (10119), 462-512.

Leibbrand, Christine, \& Crowder, Kyle. (2018). Migration, Mobility, and Neighborhood Attainment: Using the PSID to Understand the Processes of Racial Stratification. The ANNALS of the American Academy of Political and Social Science, 680(1), 172-192.

Liebe, Ulf, Preisendörfer, Peter., \& Meyerhoff, Jürgen. (2010). To Pay or Not 
to Pay: Competing Theories to Explain Individuals' Willingness to Pay for Public Environmental Goods. Environment and Behavior, 43(1), 106-130.

Logan, John R., Zhang, Wenquan, \& Alba, Richard D. (2002). Immigrant Enclaves and Ethnic Communities in New York and Los Angeles. American Sociological Review, 67(2), 299-322.

Long, J. Scott, \& Mustillo, Sarah A. (2018). Using Predictions and Marginal Effects to Compare Groups in Regression Models for Binary Outcomes. Sociological Methods 8 Research, 1-37.

Massey, Douglas S., \& Denton, Nancy A. (1993). American Apartheid: Segregation and the Making of the Underclass. Cambridge, Mass: Harvard Univ. Press.

Meyer, Reto, \& Liebe, Ulf. (2010). Are the Affluent Prepared to Pay for the Planet? Explaining Willingness to Pay for Public and Quasi-Private Environmental Goods in Switzerland. Population and Environment, 32(1), 42-65.

Mize, Trenton. (2019). Best Practices for Estimating, Interpreting, and Presenting Nonlinear Interaction Effects. Sociological Science, 6, 81-117.

Mohai, Paul, \& Saha, Robin. (2015). Which Came First, People or Pollution? A Review of Theory and Evidence from Longitudinal Environmental Justice Studies. Environmental Research Letters, 10(12), 125011.

Mundlak, Yair. (1978). On the Pooling of Time Series and Cross Section Data. Econometrica, 46(1), 69.

Noonan, Douglas S., Krupka, Douglas J., \& Baden, Brett M. (2007). Neighborhood Dynamics and Price Effects of Superfund Site Clean-Up. Journal of Regional Science, 47(4), 665-692.

Pais, Jeremy, Crowder, Kyle, \& Downey, Liam. (2014). Unequal Trajectories: Racial and Class Differences in Residential Exposure to Industrial Hazard. Social Forces, 92(3), 1189-1215.

Pasetto, Roberto, Mattioli, Benedetta, \& Marsili, Daniela. (2019). Environmental Justice in Industrially Contaminated Sites. A Review of Scientific Evidence in the WHO European Region. International Journal of Environmental Research and Public Health, 16(6), 1-20.

Pastor, Manuel, Sadd, Jim, \& Hipp, John R. (2001). Which Came First? Toxic Facilities, Minority Move-in, and Environmental Justice. Journal of Urban Affairs, 23(1), 1-21.

Quillian, Lincoln. (2012). Segregation and Poverty Concentration: The Role of Three Segregations. American Sociological Review, 777(3), 354-379.

Quillian, Lincoln. (2015). A Comparison of Traditional and Discrete-Choice Approaches to the Analysis of Residential Mobility and Locational Attain- 
ment. The ANNALS of the American Academy of Political and Social Science, $660(1), 240-260$.

Quillian, Lincoln, Heath, Anthony, Pager, Devah, Midtbøen, Arnfinn, Fleischmann, Fenella, \& Hexel, Ole. (2019). Do Some Countries Discriminate More than Others? Evidence from 97 Field Experiments of Racial Discrimination in Hiring. Sociological Science, 6, 467-496.

Rüttenauer, Tobias. (2018). Neighbours Matter: A Nation-Wide Small-Area Assessment of Environmental Inequality in Germany. Social Science Research, 70, 198-211.

Rüttenauer, Tobias. (2019). Bringing Urban Space Back in: A Multilevel Analysis of Environmental Inequality in Germany. Urban Studies, 56(12), 25492567 .

South, Scott J., \& Crowder, Kyle. (1997). Escaping Distressed Neighborhoods: Individual, Community, and Metropolitan Influences. American Journal of Sociology, 102(4), 1040-1084.

South, Scott J., Huang, Ying, Spring, Amy, \& Crowder, Kyle. (2016). Neighborhood Attainment over the Adult Life Course. American Sociological Review, $81(6), 1276-1304$.

Turner, Margery A., \& Ross, Stephen. (2005). How Racial Discrimination Affects the Search for Housing. In De Souza Briggs, Xavier N. (Ed.), The Geography of Opportunity (pp. 81-100). Washington D.C: Brookings Institution Press.

Wooldridge, Jeffrey M. (2010). Econometric Analysis of Cross Section and Panel Data. Cambridge, Mass.: MIT Press. 


\section{Appendix A. Regression model output}

Table A1. Correlated random effects probit. Dependent variable: move-out.

\begin{tabular}{|c|c|c|c|c|c|}
\hline & M1 & M2 & M3 & M4 & M5 \\
\hline Air pollution $t_{t-1}$ & $\begin{array}{c}0.051 \\
(0.038)\end{array}$ & $\begin{array}{c}-0.013 \\
(0.039)\end{array}$ & $\begin{array}{l}0.177^{* * *} \\
(0.024)\end{array}$ & $\begin{array}{l}0.125^{* * *} \\
(0.024)\end{array}$ & $\begin{array}{c}0.003 \\
(0.041)\end{array}$ \\
\hline Household income $_{t-1}$ & $\begin{array}{l}-0.208^{* * *} \\
(0.050)\end{array}$ & $\begin{array}{l}-0.191^{* * *} \\
(0.048)\end{array}$ & & & $\begin{array}{l}-0.182^{* * *} \\
(0.048)\end{array}$ \\
\hline Income $_{t-1} \times$ pollution $_{t-1}$ & $\begin{array}{l}0.080^{* *} \\
(0.025)\end{array}$ & $\begin{array}{l}0.092^{* * *} \\
(0.026)\end{array}$ & & & $\begin{array}{l}0.087^{* * *} \\
(0.026)\end{array}$ \\
\hline \multicolumn{6}{|l|}{ Minority (ref = German) } \\
\hline 1st generation $\times$ pollution $_{t-1}$ & & & $\begin{array}{r}-0.123^{*} \\
(0.058)\end{array}$ & $\begin{array}{r}-0.107 \\
(0.059)\end{array}$ & $\begin{array}{r}-0.080 \\
(0.059)\end{array}$ \\
\hline 2 nd generation $\times$ pollution $_{t-1}$ & & & $\begin{array}{c}0.050 \\
(0.099)\end{array}$ & $\begin{array}{c}0.074 \\
(0.097)\end{array}$ & $\begin{array}{c}0.067 \\
(0.096)\end{array}$ \\
\hline Basic controls & yes & yes & yes & yes & yes \\
\hline Additional controls & no & yes & no & yes & yes \\
\hline$A I C$ & 15343 & 14818 & 15364 & 14832 & 14821 \\
\hline $\operatorname{loglik}$ & -7630 & -7348 & -7639 & -7353 & -7344 \\
\hline $\mathrm{N}$ households & 3789 & 3789 & 3789 & 3789 & 3789 \\
\hline $\mathrm{N}$ & 13239 & 13239 & 13239 & 13239 & 13239 \\
\hline
\end{tabular}

${ }^{* * *} p<0.001,{ }^{* *} p<0.01,{ }^{*} p<0.05$, twotailed test. Cluster robust standard errors in parentheses. SOEP waves: 1986, 1994, 1999, 2004, 2009, 2014, 2016. Basic controls: year, age (5-year interval dummies). Additional controls: child(ren) in hh, partner in hh, distance to city centre, flat condition. All covaraites are also included as household-specific mean (omitted in output). 


\section{Appendix B. Robustness checks}

Table B1. Fixed-effects logit. Dependent variable: move-out.

\begin{tabular}{|c|c|c|c|c|c|}
\hline & M1 & M2 & M3 & M4 & M5 \\
\hline Air pollution ${ }_{t-1}$ & $\begin{array}{c}0.039 \\
(0.053)\end{array}$ & $\begin{array}{c}-0.042 \\
(0.055)\end{array}$ & $\begin{array}{l}0.220^{* * *} \\
(0.031)\end{array}$ & $\begin{array}{l}0.154^{* * *} \\
(0.033)\end{array}$ & $\begin{aligned}-0.022 \\
(0.059)\end{aligned}$ \\
\hline Household income $_{t-1}$ & $\begin{array}{l}-0.229^{* *} \\
(0.071)\end{array}$ & $\begin{array}{l}-0.211^{* *} \\
(0.072)\end{array}$ & & & $\begin{array}{l}-0.200^{* *} \\
(0.072)\end{array}$ \\
\hline Income $_{t-1} \times$ pollution $_{t-1}$ & $\begin{array}{l}0.118^{* * *} \\
(0.034)\end{array}$ & $\begin{array}{l}0.135^{* * *} \\
(0.035)\end{array}$ & & & $\begin{array}{l}0.129^{* * *} \\
(0.036)\end{array}$ \\
\hline \multicolumn{6}{|l|}{ Minority (ref = German) } \\
\hline 1st generation $\times$ pollution $_{t-1}$ & & & $\begin{array}{r}-0.164^{*} \\
(0.076)\end{array}$ & $\begin{array}{c}-0.134 \\
(0.078)\end{array}$ & $\begin{array}{c}-0.095 \\
(0.079)\end{array}$ \\
\hline 2 nd generation $\times$ pollution $_{t-1}$ & & & $\begin{array}{c}0.055 \\
(0.138)\end{array}$ & $\begin{array}{c}0.074 \\
(0.141)\end{array}$ & $\begin{array}{c}0.073 \\
(0.140)\end{array}$ \\
\hline Basic controls & yes & yes & yes & yes & yes \\
\hline Additional controls & no & yes & no & yes & yes \\
\hline$A I C$ & 7840 & 7476 & 7849 & 7488 & 7478 \\
\hline loglik & -3897 & -3705 & -3901 & -3711 & -3704 \\
\hline $\mathrm{N}$ households & 3790 & 3790 & 3790 & 3790 & 3790 \\
\hline $\mathrm{N}$ & 13241 & 13241 & 13241 & 13241 & 13241 \\
\hline
\end{tabular}

${ }^{* * *} p<0.001,{ }^{* *} p<0.01,{ }^{*} p<0.05$, twotailed test. Cluster robust standard errors in parentheses. SOEP waves: 1986, 1994, 1999, 2004, 2009, 2014, 2016. Basic controls: year, age (5-year interval dummies). Additional controls: child(ren) in hh, partner in hh, distance to city centre, flat condition.

Table B2. Fixed-effects linear probability model. Dependent variable: move-out.

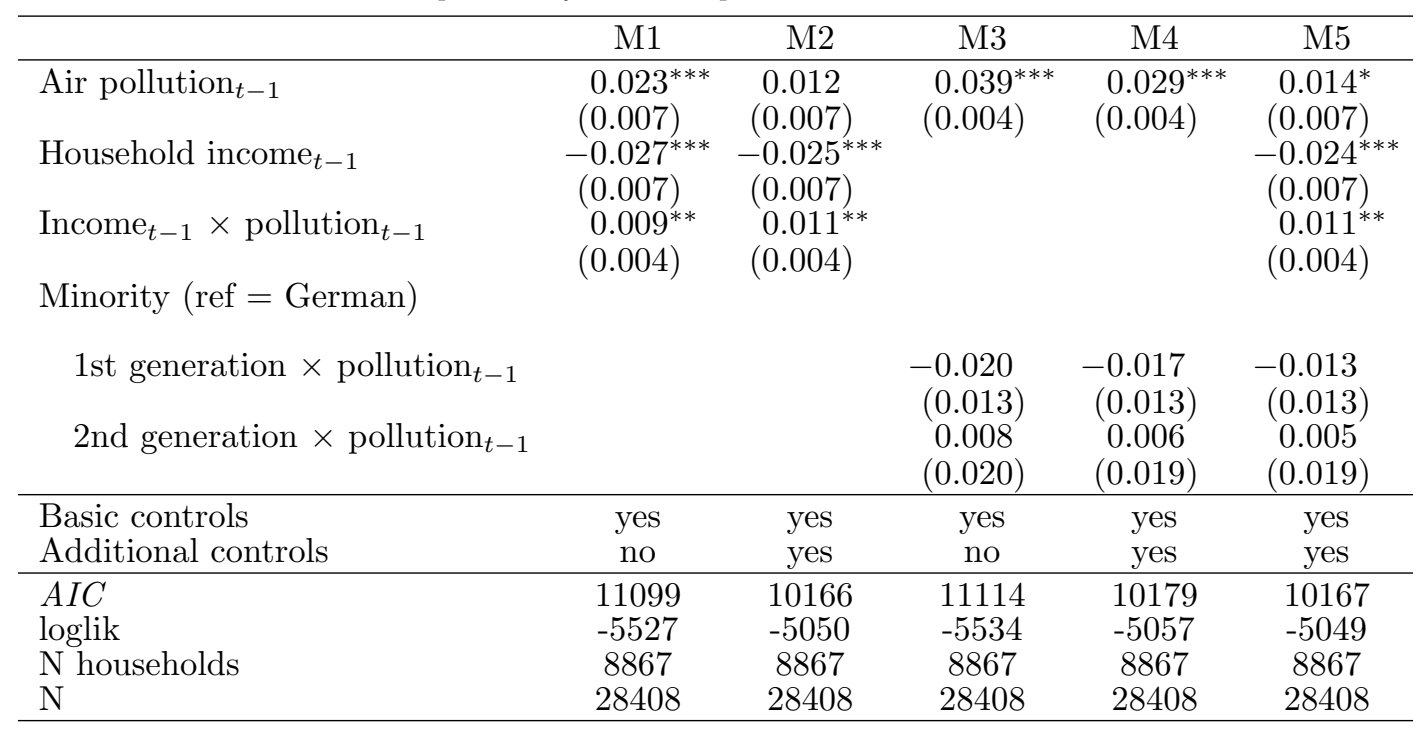

${ }^{* * *} p<0.001,{ }^{* *} p<0.01,{ }^{*} p<0.05$, twotailed test. Cluster robust standard errors in parentheses. SOEP waves: 1986, 1994, 1999, 2004, 2009, 2014, 2016. Basic controls: year, age (5-year interval dummies). Additional controls: child(ren) in hh, partner in hh, distance to city centre, flat condition. 


\section{Online Supplement}

\section{Appendix S3. Full sample (including households without within-variance on moving variable)}

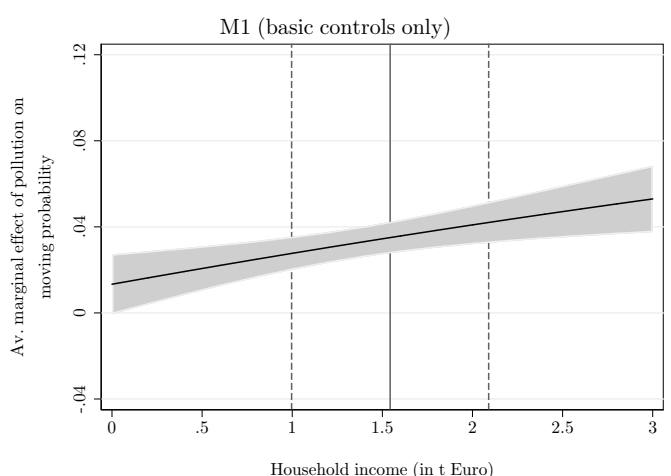

Figure S1. AME of air pollution on the likelihood of moving out conditional on income (M1) with $95 \%$ CI. Dashed lines mark +/- one within SD from the mean.

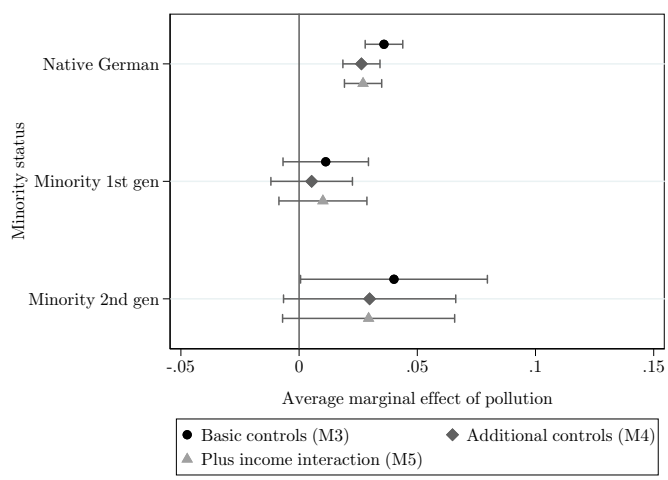

Figure S3. AME of air pollution on the likelihood of moving out conditional on minority status (M3-M5) with $95 \%$ CI.

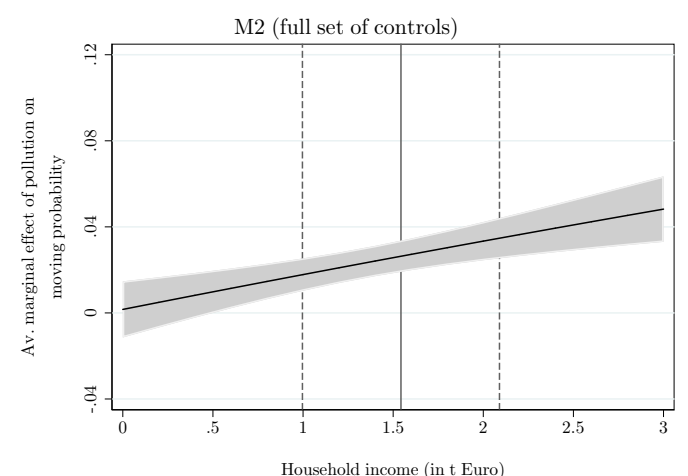

Figure S2. AME of air pollution on the likelihood of moving out conditional on income (M2) with $95 \%$ CI Dashed lines mark +/- one within SD from the mean.

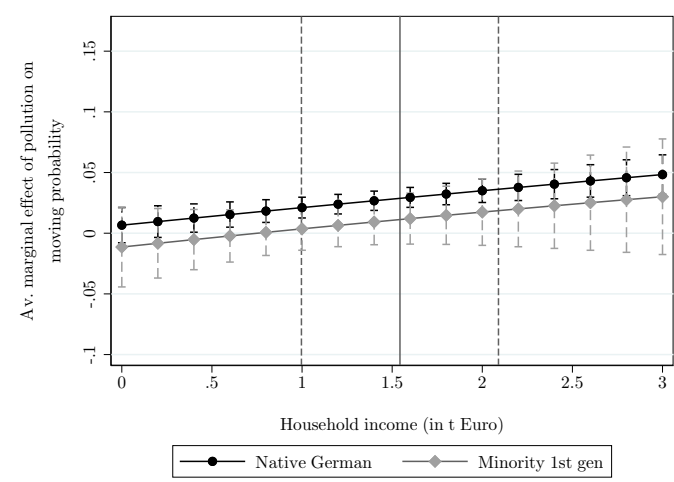

Figure S4. AME of air pollution on the likelihood of moving out conditional on income (M6) with $95 \%$ CI. Short-dashed lines mark +/- one within SD from the mean. 
Table S1. Correlated random effects probit. Dependent variable: move-out.

\begin{tabular}{|c|c|c|c|c|c|}
\hline & M1 & M2 & M3 & M4 & M5 \\
\hline Air pollution pl-1 $_{t}$ & 0.056 & 0.007 & $0.159^{* * *}$ & $0.122^{* * *}$ & 0.024 \\
\hline & $(0.030)$ & $(0.030)$ & $(0.018)$ & $(0.018)$ & $(0.031)^{*}$ \\
\hline Household income $t-1$ & $\begin{array}{l}-0.171^{* a x} \\
(0.039)\end{array}$ & $\begin{array}{l}-0.1622^{* a x} \\
(0.038)\end{array}$ & & & $\begin{array}{l}-0.156^{\text {Nat }} \\
(0.038)\end{array}$ \\
\hline Income $_{t-1} \times$ pollution $_{t-1}$ & $0.065^{* * *}$ & $0.075^{* * *}$ & & & $0.070^{* * *}$ \\
\hline \multicolumn{6}{|l|}{ Minority (ref = German) } \\
\hline 1st generation $\times$ pollution $_{t-1}$ & & & $-0.102^{*}$ & $-0.095^{*}$ & -0.074 \\
\hline 2nd generation $\times$ pollution & & & $(0.047)$ & $\begin{array}{c}(0.048) \\
0.013\end{array}$ & $\begin{array}{c}(0.048) \\
0.009\end{array}$ \\
\hline 2nu generation $x$ ponution $t-1$ & & & $(0.074)$ & $(0.075)$ & $(0.075)$ \\
\hline Basic controls & yes & yes & yes & yes & yes \\
\hline Additional controls & no & yes & no & yes & yes \\
\hline$A I C$ & 24592 & 23752 & 24590 & 23721 & 23707 \\
\hline $\operatorname{loglik}$ & -12255 & -11815 & -12252 & -11798 & -11786 \\
\hline $\mathrm{N}$ households & 8863 & 8863 & 8863 & 8863 & 8863 \\
\hline $\mathrm{N}$ & 28393 & 28393 & 28393 & 28393 & 28393 \\
\hline
\end{tabular}

${ }^{* * *} p<0.001,{ }^{* *} p<0.01,{ }^{*} p<0.05$, twotailed test. Cluster robust standard errors in parentheses. SOEP waves: 1986, 1994, 1999, 2004, 2009, 2014, 2016. Basic controls: year, age (5-year interval dummies). Additional controls: child(ren) in hh, partner in hh, distance to city centre, flat condition. All covaraites are also included as household-specific mean (omitted in output). 


\section{Appendix S4. Analyses using inverse probability of staying weights}

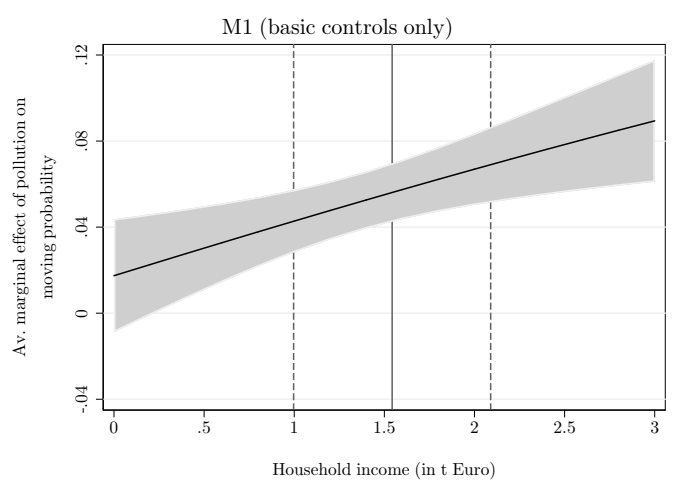

Figure S1. AME of air pollution on the likelihood of moving out conditional on income (M1) with $95 \%$ CI. Dashed lines mark +/- one within SD from the mean.

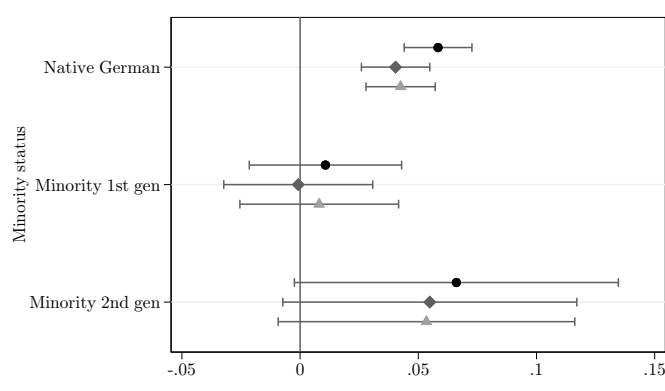

$$
\begin{array}{|l|}
\multicolumn{1}{c}{\text { Average marginal effect of pollution }} \\
\hline \text { - Basic controls (M3) } \\
\Delta \text { Plus income interaction (M5) }
\end{array}
$$

Figure S3. AME of air pollution on the likelihood of moving out conditional on minority status (M3-M5) with $95 \% \mathrm{CI}$.

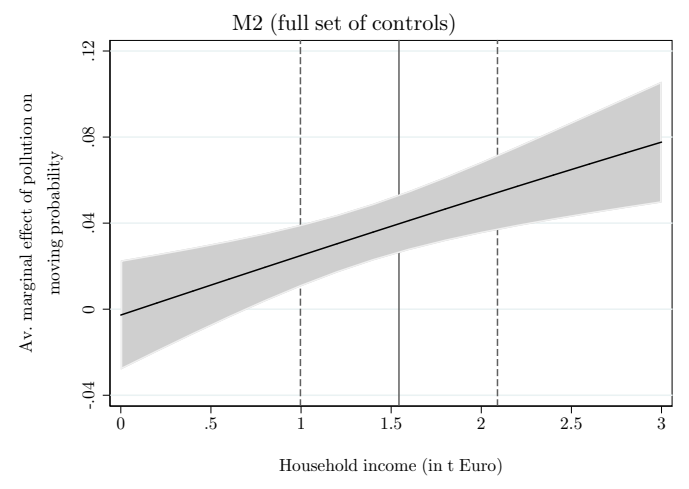

Figure S2. AME of air pollution on the likelihood of moving out conditional on income (M2) with 95\% CI. Dashed lines mark +/- one within SD from the mean.

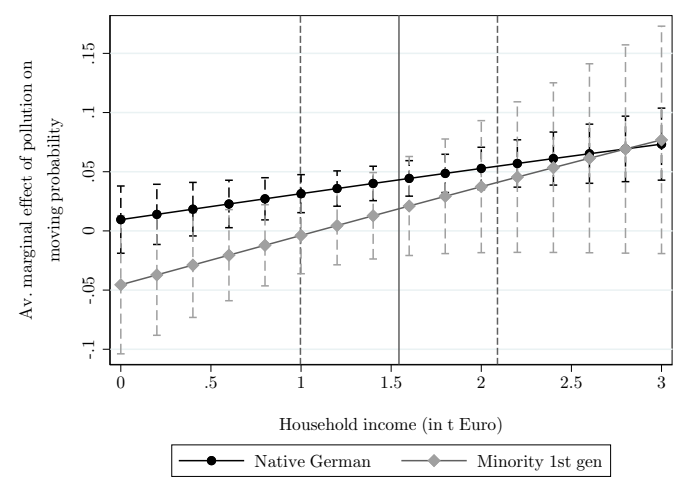

Figure S4. AME of air pollution on the likelihood of moving out conditional on income (M6) with $95 \%$ CI. Short-dashed lines mark +/- one within SD from the mean. 
Table S1. CRE probit with inverse probability of staying weights. Dependent variable: move-out.

\begin{tabular}{|c|c|c|c|c|c|}
\hline & M1 & M2 & M3 & M4 & M5 \\
\hline Air pollution $t_{t-1}$ & $\begin{array}{c}0.051 \\
(0.039)\end{array}$ & $\begin{array}{c}-0.008 \\
(0.040)\end{array}$ & $\begin{array}{l}0.177^{* * *} \\
(0.023)\end{array}$ & $\begin{array}{l}0.127^{* * *} \\
(0.023)\end{array}$ & $\begin{array}{c}0.014 \\
(0.042)\end{array}$ \\
\hline Household income $_{t-1}$ & $-0.210^{* * *}$ & $\begin{array}{l}-0.191^{* * *} \\
(0.050)\end{array}$ & & & $\begin{array}{l}-0.179^{* * *} \\
(0.050)\end{array}$ \\
\hline Income $_{t-1} \times$ pollution $_{t-1}$ & $\begin{array}{l}0.077^{* *} \\
(0.025)\end{array}$ & $\begin{array}{l}0.087^{* * *} \\
(0.025)\end{array}$ & & & $\begin{array}{l}0.080^{* *} \\
(0.026)\end{array}$ \\
\hline \multicolumn{6}{|l|}{ Minority (ref = German) } \\
\hline 1st gen minority $\times$ pollution $_{t-1}$ & & & $\begin{array}{r}-0.140^{*} \\
(0.059)\end{array}$ & $\begin{array}{r}-0.130^{*} \\
(0.061)\end{array}$ & $\begin{array}{c}-0.103 \\
(0.061)\end{array}$ \\
\hline 2 nd minority $\times$ pollution $_{t-1}$ & & & $\begin{array}{c}0.038 \\
(0.103)\end{array}$ & $\begin{array}{c}0.056 \\
(0.099)\end{array}$ & $\begin{array}{c}0.048 \\
(0.098)\end{array}$ \\
\hline Basic controls & yes & yes & yes & yes & yes \\
\hline Additional controls & no & yes & no & yes & yes \\
\hline$A I C$ & 16531 & 15982 & 16549 & 15992 & 15982 \\
\hline loglik & -8225 & -7931 & -8232 & -7934 & -7925 \\
\hline $\mathrm{N}$ households & 3766 & 3766 & 3766 & 3766 & 3766 \\
\hline $\mathrm{N}$ & 13066 & 13066 & 13066 & 13066 & 13066 \\
\hline
\end{tabular}

${ }^{* * *} p<0.001,{ }^{* *} p<0.01,{ }^{*} p<0.05$, twotailed test. Cluster robust standard errors in parentheses. SOEP waves: 1986, 1994, 1999, 2004, 2009, 2014, 2016. Basic controls: year, age (5-year interval dummies). Additional controls: child(ren) in hh, partner in hh, distance to city centre, flat condition. All covaraites are also included as household-specific mean (omitted in output). 